\title{
When colors backfire: The impact of color cues on moral judgment
}

\author{
Tine De Bock ${ }^{\mathrm{a}, *}$, Mario Pandelaere ${ }^{\mathrm{b}}$, Patrick Van Kenhove ${ }^{\mathrm{b}}$ \\ ${ }^{a}$ Hogeschool-Universiteit Brussel, Faculty of Economics and Management, Human Relations Research Group, Warmoesberg 26, 1000 Brussels, Belgium \\ ${ }^{\mathrm{b}}$ Ghent University, Faculty of Economics and Business Administration, Department of Marketing, Tweekerkenstraat 2, 9000 Ghent, Belgium
}

Received 29 September 2011; received in revised form 20 September 2012; accepted 21 September 2012

Available online $\mathrm{xxxx}$

\begin{abstract}
This article investigates if and how the valence of color cues affects moral acceptability of (un)desirable consumer behaviors. Study 1 uses colors with definite differences in terms of valence, namely, red and green. 'Study 2 applies an evaluative conditioning paradigm to endow initially neutral colors with negative versus positive valences. We find an ironic color effect: undesirable behaviors become more acceptable when presented with negatively valenced colors. In general, respondents find (un)desirable behaviors more acceptable when a background color is of the same valence rather than neutral or opposite in valence. Implications for promotion and prevention campaigns are discussed.

(C) 2012 Society for Consumer Psychology. Published by Elsevier Inc. All rights reserved.
\end{abstract}

Keywords: Affective priming; Color; Moral judgment; Conceptual fluency; Intuition

\section{Introduction}

Colors are ubiquitous. The objects, people, and environments we daily face all contain color information. As Mehta and Zhu (2009) remark: "color is a fundamental aspect of human perception" (p. 1226). Colors also entail more than just esthetics in that they carry psychological meanings and associations. The current paper investigates if and how the valence of color cues might affect evaluations of positively and negatively valenced behaviors. ${ }^{1}$ Intriguingly, our findings show an ironic color effect: using colors with a negative valence in campaigns aiming to prevent negatively valenced behavior may actually backfire as it renders undesirable behavior less negative.

This study contributes to several research lines. First, we add to the emerging stream of research on color functioning (e.g., Bagchi \& Cheema, 2013; Deng, Hui, \& Hutchinson, 2010; Lindsey et al.,

* Corresponding author.

E-mail addresses: tine.debock@hubrussel.be (T. De Bock),

Mario.Pandelaere@UGent.be (M. Pandelaere), Patrick.VanKenhove@Ugent.be (P. Van Kenhove).

${ }^{1}$ The terms bad, negative, unwanted, undesirable, unacceptable and immoral are used interchangeably in this article, and so are the terms good, positive, wanted, desirable, acceptable and moral.
2010). Several studies indicate the positive consequences of the color red (e.g., red as an effective hazard warning color; Chan \& $\mathrm{Ng}, 2009)$. In contrast, this study demonstrates the backfire effect of this color as it may lead to a less negative evaluation of deviant behavior. Second, this backfire effect contrasts with several studies that document match effects, such that a match between a message cue and the message content exerts beneficial effects on judgment and persuasion (e.g., Cavazza, Graziani, Serpe, \& Rubichi, 2010; Mayer \& Tormala, 2010). This study instead reveals the potential detrimental effects of a valence match between a cue and a message on moral judgments. Third, moral judgments have traditionally been considered as the result of rational and deliberate reasoning processes (e.g., Jones, 1991; Kohlberg, 1976; Turiel, 1983). More recently, scholars have argued and showed that moral decision making is also influenced, if not dominated, by intuitive factors (e.g., Haidt, 2001; Meier, Robinson, \& Clore, 2004). The current paper supports this latter argument by demonstrating the effect of seemingly irrelevant color cues on moral judgment.

Fourth, this research adds to previous fluency research in many ways. While previous studies mainly focus on perceptual fluency, this study examines the role of conceptual fluency (Lee \& Labroo, 2004). Further, our study identifies an important and 
ubiquitous source of conceptual fluency that has been previously overlooked, namely, fluency stemming from a match between the valence of a stimulus and its context, rather than from semantic priming. Moreover, this study complies with the demand for more research on the effect of fluency on evaluative judgments other than malleable preference and liking judgments previously investigated (Winkielman, Schwarz, Fazendeiro, \& Reber, 2003). In addition, no research ever examined the role of conceptual fluency in the moral domain. Finally, as this study shows that fluency may render clearly valenced complex, linguistic stimuli (viz. behavior descriptions) more positive (or less negative), we demonstrate the more general and robust nature of fluency effects compared to previous studies involving mainly perceptual and simple neutral or new stimuli.

Our findings are important for a host of settings. For example, marketers and policy makers attempt to develop messages that discourage undesirable behaviors, often by appeals to moral judgment and behavior. Such decision makers need to consider the effects of colors carefully, because they might assume a negative connotation color, such as red, to aid to deter people from a bad behavior, whereas these messages may inadvertently render the undesirable behavior less negative. This result goes against the common intuition that negative colors are better suited to mitigate undesirable behavior compared to positive colors (see pilot study later), and challenges the idea of the color red being advantageous by grabbing people's attention. Our findings also suggest that undesirable behavior, like petty crime, might be more likely if the physical environment prompts negative evaluations.

\section{Theoretical framework}

In many situations, particular colors get paired with particular messages, concepts, and experiences (Elliot, Maier, Moller, Friedman, \& Meinhardt, 2007). Through repeated pairings, people form strong color associations (Mehta \& Zhu, 2009), such that the mere presence of a color in a situation can activate corresponding associations that influence affect, cognition, and behavior (Elliot, Maier, Binser, Friedman, \& Pekrun, 2009). Two colors that are of interest for written communication to indicate desirability or undesirability are green and red, respectively. Red, as typically associated with dangers and mistakes (e.g., traffic lights, stop signs, warning signals; Elliot et al., 2007), activates an avoidance motivation (Mehta \& Zhu, 2009), making people more vigilant and risk averse (Friedman \& Förster, 2002, 2005). Green contrasts chromatically and psychologically with red and offers general associations with approach motivations (Elliot \& Maier, 2007). Briefly stated, colors that convey positive meanings (e.g., green) generally induce approach responses, whereas colors carrying negative meanings (e.g., red) induce avoidance responses.

It thus seems reasonable to argue that using the color red should enhance communications aimed at reducing unwanted behavior, while using green should improve campaigns aimed at inducing wanted behavior. Indeed, we conducted a pilot study in which participants indicated which color (i.e. red or green) they find more suited for campaigns aimed at stimulating good behavior $(N=45)$ or deterring bad behavior $(N=46)$. We found a significant association between color and type of campaign, $\chi^{2}(1)=50.25, p<.001$. Results showed that $93 \%$ preferred green over red for stimulating good behavior, and $80 \%$ preferred red over green for deterring bad behavior. In both cases, the observed percentages differ from indifference (i.e. 50\%), $z \mathrm{~s}>5.19, p \mathrm{~s}<.001$. In a second pilot test, a convenience sample of marketers and communication specialists who are involved in the development of promotion and/or prevention campaigns indicated which color (i.e. red or green) they considered most effective to decrease undesirable behavior $(N=12)$ or to increase desirable behavior $(N=13)$. A significant association between color and type of campaign emerged, $\chi^{2}(1)=9.00, p=.003$. To reduce undesirable behavior, $75 \%$ would use red rather than green while to increase desirable behavior, $85 \%$ would use green rather than red. This pattern of results is not different from that of our first pilot test, $\chi^{2}(1)=1.04, p=.31$.

Based on affective priming and fluency theory, this study suggests alternative predictions for the commonly held belief that negative (vs. positive) color cues are better suited for messages to prevent negative behavior. Affective priming refers to the fact that people process targets faster and more accurately if they are preceded by primes with the same rather than an opposite valence (see Fazio, 2001; Klauer \& Musch, 2003). For example, people identify the word cancer faster when it is preceded by the word spider than by the word flower. Affective priming even occurs when the prime and target appear simultaneously instead of sequentially (e.g., Spruyt, Hermans, De Houwer, Vandromme, \& Eelen, 2007). Although affective priming studies generally use simple primes and targets (i.e. single words or pictures of an easily identified object), this phenomenon may be relevant for more complex stimuli too.

In affective priming, a valenced prime is presumed to activate the corresponding valence which makes it easier to activate concepts with a similar valence (Fazio, 2001). Although never recognized as such, affective priming may thus imply a form of conceptual fluency, which arises when the mental representation of a target is easier to activate because it offers semantic relatedness to the context in which it appears (Whittlesea, 1993). If we designate a background color as prime and an (un)desirable behavior as target, a valence match between the background color and the behavior might generate conceptual fluency. In the moral domain, a red background color entails a context that is associated with something bad. Consequently, one may experience conceptual fluency when processing a bad behavior described on a red background. A green background color, on the other hand, entails a context that is related to something good. Therefore, one may experience conceptual fluency when processing a good behavior described on a green background.

Such conceptual fluency represents a specific form of processing fluency. In general, experiencing processing fluency evokes a positive affective state that people misattribute to the stimuli they are processing rather than to the ease of processing (Winkielman et al., 2003), thereby affecting a myriad of perceptions as liking (Reber, Winkielman, \& Schwarz, 1998), esthetic appreciation (Pandelaere, Millet, \& Van den Bergh, 2010; Reber, Schwarz, \& Winkielman, 2004) and importance 
ratings (Shah \& Oppenheimer, 2007). To cite one example, people regard their childhood memories as more intact when they must recall four episodes from their childhood instead of twelve (Winkielman, Schwarz, \& Belli, 1998), presumably because retrieving just four episodes is easier than retrieving twelve episodes. This ease (vs. difficulty) during the retrieval task then gets attributed not to the task at hand but rather to the quality of childhood memory.

We similarly propose that people may view any given (un) desirable behavior as more positive or less negative if its valence matches the valence of the background on which it is described. So, we predict that a good behavior would be viewed as even more positive when described on a green (vs. red) background while a bad behavior would be viewed as less negative when described on a red (vs. green) background. This prediction was tested in Study 1. In this study, participants viewed descriptions of desirable or undesirable consumer behaviors, which they evaluated on moral acceptability. The descriptions of these desirable or undesirable consumer behaviors appeared on either a red or green background.

\section{Study 1}

\section{Participants and procedure}

One hundred twenty-seven respondents (41 men, 86 women) between 18 and 68 years old $(M=33.05, S D=13.57)$ were randomly assigned to the conditions of a two (behavior: undesirable vs. desirable) by two (background color: red vs. green) between-subjects design. Participants rated the acceptability of four desirable or undesirable consumer behaviors (in random order). The first scenario involved a consumer receiving too much change at a checkout. In the undesirable behavior condition, the consumer did not mention the error to the cashier and kept the extra change. In the desirable behavior condition, the consumer told the cashier and returned the extra change. In the second scenario, a consumer downloaded music from the Internet either legally or illegally. The third scenario entailed a consumer who, upon leaving a supermarket, noticed that he or she had not been charged for a particular item and either did or did not go back to pay for it. Finally, the fourth scenario described a consumer who took a soft drink from the store shelf, drank it in the store, and did or did not pay for it at the checkout.

These four consumer behaviors were described on either a red or green background. Participants rated the acceptability of the four consumer behaviors on a Likert scale, ranging from "completely unacceptable" (1) to "completely acceptable" (7). After these moral judgments, participants rated the background color on which the (un)desirable behaviors were described on two seven-point semantic differential scales, with the anchor points "wrong" versus "right" and "negative" versus "positive."

\section{Results and discussion}

As a manipulation check, we created a color valence index by averaging the wrong-right and negative-positive ratings $(\alpha=$ .86 ). The ANOVA used behavior (desirable vs. undesirable) and background color (red vs. green) as between-subjects independent variables and the color valence index as the dependent variable. As intended, only a significant main effect of background color emerged, $F(1,123)=44.89, p<.001$. Specifically, red was rated as more negative $(M=3.52, S D=1.75)$ than green $(M=5.27, S D=1.08)$. Further, red was regarded as more negative $(p=.028)$, and green as more positive $(p<.001)$, than the neutral midpoint of 4 .

To test our hypothesis, we averaged the acceptability ratings across the four scenarios $(\alpha=.78)$ and subjected them to a between-subjects ANOVA with behavior and background color as factors. The significant main effect of behavior, $F(1,123)=$ $134.75, p<.001$, showed that undesirable consumer behaviors $(M=4.17, S D=1.11)$ were less accepted than the desirable ones $(M=6.09, S D=0.81)$. We also identified a significant interaction effect between behavior and background color, $F(1,123)=14.68$, $p<.001$ (see Fig. 1). Desirable consumer behaviors were perceived as more positive when described on a green background $(M=6.33$, $S D=0.53)$ rather than a red background $(M=5.85, S D=0.95)$, $F(1,58)=5.68, p=.020$. Conversely, undesirable consumer behaviors were perceived as more negative on a green background $(M=$ $3.78, S D=0.76)$ than on a red background $(M=4.56, S D=1.24)$, $F(1,65)=9.47, p=.003$. Finally, we found no significant main effect of background color, $F(1,123)=.84, p=.36$.

In summary, the results of Study 1 confirm our hypothesis. That is, a valence match between a behavior and a background color on which this behavior is described affects moral judgments of that behavior. In other words, desirable behaviors are rated as more positive when described on a green background than on a red background, while undesirable behaviors are rated as less negative when described on a red background than on a green background. The latter finding contrasts with the lay belief demonstrated in both pilot studies that negative colors such as red are better suited to prevent negative behavior.

\section{Study 2}

In Study 1, we did not manipulate the valence of the background colors and relied instead on the associations of red with negativity and green with positivity. The effects obtained

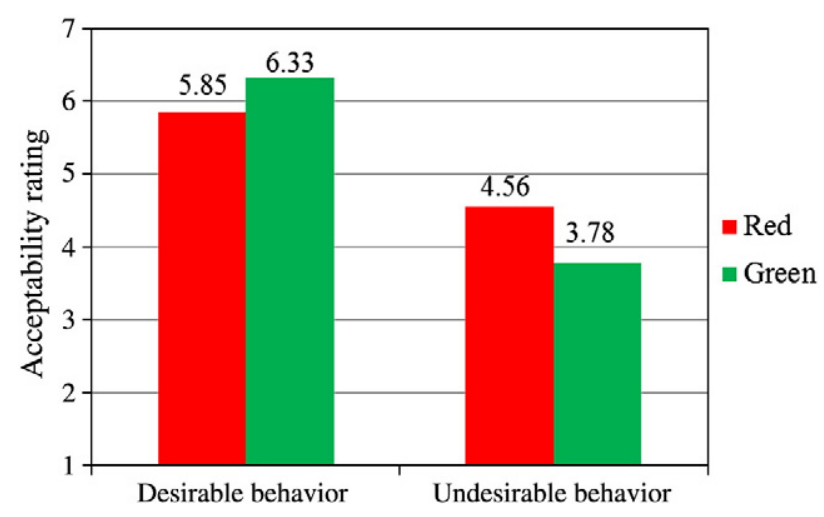

Fig. 1. Study 1: interaction between behavior and background color. 
in Study 1 could therefore be due to differences in specific associations with red and green rather than to their difference in valence. To rule out this alternative interpretation, Study 2 aims to replicate the effect of the color-behavior valence match on moral judgments by endowing initially neutral colors with either positive or negative valences through an evaluative conditioning procedure (i.e. a procedure that changes the liking of a stimulus through pairing that stimulus with positive or negative stimuli; for an overview, see De Houwer, 2011; Hofmann, De Houwer, Perugini, Baeyens, \& Crombez, 2010).

Further, one may wonder whether the obtained effects are due to experiencing processing fluency in case of behavior-color valence matches, or rather to experiencing processing difficulty in case of behavior-color valence mismatches (i.e. disfluency). In particular, it could be that people consider describing behaviors on backgrounds with opposite valences as inappropriate or odd, as a result of which valence mismatches lead to less positive or more negative moral acceptability judgments (compared to the situation in which behaviors are described on backgrounds with similar or neutral valences). To investigate this possibility, Study 2 adds control conditions in which the (un)desirable behaviors are described on neutral colors (i.e. the colors that are endowed with either a positive or negative valence in the other conditions). This allows examining whether the obtained effects are due to valence matches and/or valence mismatches.

\section{Participants and procedure}

Respondents ( $N=149,52$ men, 97 women; aged $18-72$ years, $M=29.64, S D=13.40)$ were randomly assigned to the conditions of a two (behavior: undesirable vs. desirable) by two (background color valence: negative vs. positive) between-subjects design. Afterwards, and based on reviewer comments, additional respondents $(N=67,38$ men, 29 women; aged 19-23 years, $M=20.63, S D=0.94)$ were run to add control conditions to the design. They were randomly assigned to the undesirable or the desirable behavior condition; all respondents viewed the behaviors on a neutrally valenced background.

The study consisted of two parts. In the first part, participants considered 34 statements and indicated, for each statement, whether they thought it was true or not. The statements were chosen to be obscure enough so that respondents would not know the correct answer but instead would have to guess, such as " 1522 passengers died on the Titanic," "Chlorine was discovered by Carl Scheele in 1774," and "The Chinese Wall is 6259 kilometers in length." Participants received feedback about their answers indicating whether they were wrong or right.

In the different 'background color valence' conditions, the feedback (i.e. "wrong" and "right") appeared in different colors. For the participants in the negative and positive background color valence conditions, the feedback appeared in light purple and beige. For half of them, "wrong" was written in light purple and "right" in beige; for the other half of these participants, this association was reversed. We chose light purple and beige on the basis of a pretest indicating both colors prompted neutral evaluations. The aim of this first part for those participants was to endow these two initially neutral colors with either negative or positive valences through their repeated association with 'wrong' and 'right'. In the control conditions (i.e. the conditions that were added afterwards to the original $2 * 2$ between-subjects design), the colors beige and light purple were not endowed with either negative or positive valences. However, to ensure procedural similarity between conditions, we also used a knowledge test with feedback in the control conditions. The feedback, however, did not involve the colors beige and light purple but red (for negative feedback) and green (for positive feedback).

In the second part of the survey, participants rated the acceptability of either four negative or four positive consumer behaviors (which were counterbalanced), identical to those in Study 1 . These behaviors appeared on either beige or light purple backgrounds; the colors red and green only featured in the knowledge test and were not used as background colors in any of these conditions. Depending on the condition to which one was assigned in the first part of the survey, the beige and light purple backgrounds were associated with a positive, negative, or neutral valence. Participants rated the acceptability of the consumer behaviors on a Likert scale, ranging from "completely unacceptable" (1) to "completely acceptable" (7). After judging these behaviors, participants rated the background color of the scenarios (beige vs. light purple) on two seven-point semantic differential scales, with the anchor points "wrong" versus "right" and "negative" versus "positive."

\section{Results and discussion}

We averaged the background color (i.e. either light purple or beige) ratings for the wrong-right and negative-positive scales to create a color valence index $(\alpha=.75)$. As intended, colors were rated as more negative and wrong when associated with negative feedback $(M=3.42, S D=1.18)$ than with positive feedback $(M=4.35, S D=1.19 ; p<.001)$ or in the neutral conditions $(M=4.00, S D=0.34 ; p=.001)$. Further, colors were rated as more positive when associated with positive feedback than in the neutral conditions $(p=.035)$. Finally, the colors associated with the negative feedback were regarded as more negative $(p<.001)$, the colors associated with the positive feedback as more positive $(p=.014)$, and the colors used in the neutral conditions as not different $(p=.86)$ than the neutral midpoint of 4 .

We averaged the acceptability ratings across the four scenarios $(\alpha=.76)$. Because the control conditions were added afterwards, we first analyze the acceptability ratings using a 2 (behavior: desirable vs. undesirable) $* 2$ (background color valence: positive vs. negative) between-subjects ANOVA, and subsequently use $t$-tests to engage in relevant comparisons with the control conditions (in which the valence of the background color was neutral).

While the ANOVA yielded no main effect of background color valence in the experimental conditions, $F(1,145)=1.26$, $p=.263$, a significant main effect of behavior, $F(1,145)=97.75$, $p<.001$, showed that undesirable consumer behaviors were considered less acceptable $(M=4.31, S D=1.11)$ than desirable ones $(M=5.98, S D=1.02)$. As shown in Fig. 2, we also found a significant interaction effect between behavior and background 


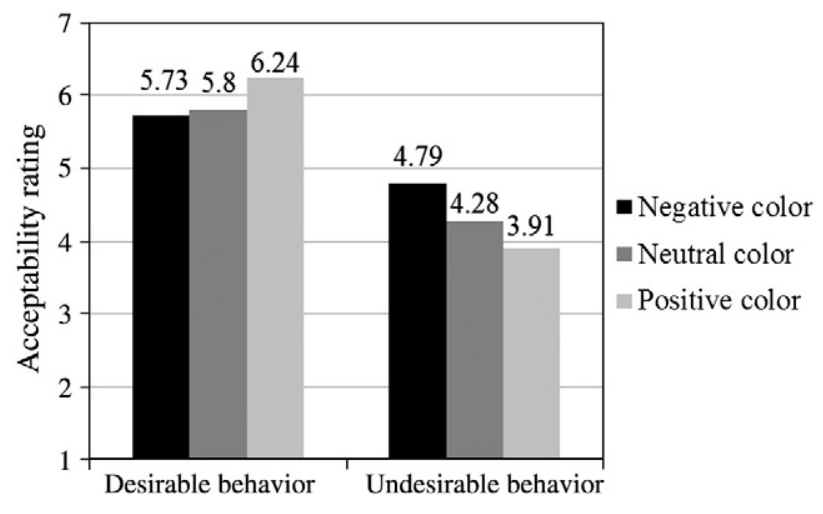

Fig. 2. Study 2: moral acceptability as a function of behavior and background color valence.

color valence, $F(1,145)=17.53, p<.001$. Desirable consumer behaviors appeared more positive in the positive background color condition $(M=6.24, S D=0.87)$ than in the negative background color condition $(M=5.73, S D=1.11 ; p=.032)$. The acceptability ratings of desirable consumer behaviors in the control (i.e. neutral background) condition $(M=5.80, S D=0.79)$ differed significantly from those in the positive background color condition, $t(74)=2.29, p=.025$, but not from those in negative background color condition, $t(74)=0.33, p=.75$.

Undesirable consumer behaviors appeared less negative in the negative background color condition $(M=4.79, S D=1.08)$ than in the positive background color condition $(M=3.91, S D=$ $0.97 ; p<.001)$. The acceptability ratings of undesirable consumer behaviors in the control (i.e. neutral background) condition $(M=4.28, S D=0.63)$ differed significantly from those in the negative background color condition, $t(60)=2.31$, $p=.024$, and marginally significantly from those in the positive background color condition, $t(67)=1.92, p=.06$.

In summary, these results replicate those of Study 1. More specifically, undesirable behaviors appear less negative when they are described with a negatively (vs. positively) valenced background while desirable behaviors are perceived as more positive when they are described on a positively (vs. negatively) valenced background. More generally, a match between the valence of an (un)desirable behavior and the valence of its color context results in more positive/less negative evaluations of the behavior.

In contrast to Study 1, we manipulated color valence rather than relied on colors with established and contrasting valence associations (i.e. red and green). This makes it more likely that the results we obtained can be attributed to color valence and not to any other specific color associations. In addition, the results of Study 2 show that the valence match effects are not limited to the colors red and green but extend to other colors with a definite valence. Further, by adding neutral conditions (i.e. undesirable or desirable behaviors described on neutral backgrounds), this second study allows to disentangle the effects of fluency (i.e., valence match) and disfluency (i.e. valence mismatch). Fluency seems to render both desirable behaviors more positive and undesirable behaviors less negative. The results for disfluency are more mixed: disfluency renders undesirable behavior somewhat more unacceptable, but did not alter the acceptability of desirable behaviors.

\section{General discussion}

Findings of Study 1 showed that people evaluate undesirable consumer behaviors less negatively when described on a red (vs. green) background while they evaluate desirable consumer behaviors more positively when described on a green (vs. red) background. In Study 2, we replicated these findings by describing various (un)desirable consumer behaviors on a background of which the color valence had been manipulated through an evaluative conditioning procedure. In line with the results of Study 1, undesirable behaviors are rated as less negative on a negative compared to a positive background while desirable behaviors are rated more acceptable when described on a positive compared to a negative background. Further, comparisons with conditions in which the (un)desirable behaviors are described on a neutral background demonstrate that fluency renders behaviors more positive or less negative, but disfluency only seems to render undesirable behavior more negative.

In many situations, written communication aims to deter people from engaging in unwanted behavior or to incite them to display wanted behavior. In addition to the content of the message, diverse elements of the presentation may determine the effectiveness of such written persuasion attempts. Various lines of research have documented so-called match or fit effects, but our findings suggest that a match between color cue valence and message valence might not always be beneficial. Colors with a positive valance may help instigate wanted behavior, but colors with a negative valence might not reduce unwanted behavior. Ironically, they may even increase their prevalence.

So from a practical point of view, these findings are useful for decision makers (e.g., marketers, policy makers) who work to improve moral judgment and behavior. Both prevention and promotion campaigns should avoid colors that exhibit a negative valence; specifically, the use of the color red appears ill conceived for promotion and prevention campaigns. This finding is notable; it not only flies in the face of common intuition that predicts increased persuasion when negative colors are used to prevent undesirable behavior (see our pilot studies), but it also defies that the color red is beneficial because it may serve to draw people's attention.

Our study also contributes to extant literature in several respects. First, our results indicate that moral decision making is not limited to conscious, rational, deliberative thinking processes, as long has been suggested (e.g., Kohlberg, 1976; Piaget, 1965; Rest, 1986). By demonstrating the effect of irrelevant color cues on moral judgment, our findings support an emerging stream of research that calls for more investigation of the importance of intuitive elements and their influence on moral judgments (e.g., Haidt, 2001).

Second, in many situations, the use of the color red has positive consequences. Research indicates that red prompts the highest levels of perceived hazard and behavioral compliance with warnings (e.g., Braun \& Silver, 1995; Chan \& Ng, 2009). Other studies show that red enhances cognitive task performance 
(e.g., Kwallek \& Lewis, 1990; Stone, 2003). Nevertheless, our findings warn that the use of the color red may backfire and result in negative consequences. It should be noted, however, that the valence associations with red and green may be culture specific (e.g., in China, red stands for luck). So, our interpretation only holds for cultures that view red as negative and green as positive.

Third, literature is replete with examples of positive effects derived from a match among message elements. Thus beautiful endorsers are more effective in endorsing beauty products than less beautiful endorsers (e.g., Kahle \& Homer, 1985; Kamins, 1990), and affective messages are better suited to change affective attitudes, whereas cognitive messages are more effective for changing cognitive attitudes (Mayer \& Tormala, 2010). People also tend to be more persuaded by messages that match, rather than mismatch, their chronic self-regulatory orientation (e.g., Adams, Faseur, \& Geuens, 2011; Zhao \& Pechmann, 2007). In contrast, and for the first time to the best of our knowledge, we find that a match may backfire in persuasive contexts. On one level, the match between color valence and message valence may be beneficial if it results in enhanced processing fluency. For prevention campaigns, however, such processing fluency may backfire when the ensuing positive affect gets attributed to the behavior, rather than the processing, and makes the negative behavior seem less unacceptable.

Fourth, our study extends research on fluency in several respects. Although perceptual and conceptual fluency are independent, distinct constructs, with their own antecedents and consequences (e.g., Cabeza \& Ohta, 1993; Lee, 2002; Tulving \& Schacter, 1990), most studies of processing fluency focus on perceptual fluency (i.e. ease with which people perceive and identify the physical characteristics of stimuli) while the number of studies on conceptual fluency is rather limited (Lee \& Labroo, 2004). Further, our research adds to the limited literature on conceptual fluency because we focus on a different aspect of this type of fluency. In fact, studies on conceptual fluency mainly use semantic priming which is very specific. Our studies show that affective priming (with color as prime and a behavior description as target) may also yield results that are compatible with conceptual fluency, which is much more general because it merely requires overlap in valence rather than in content.

Our research also extends prior literature on fluency because it shows that it not only affects preferences and liking judgments, which may be rather malleable (Simonson, 2008), but also more profound moral acceptability judgments. This answers to the call for research on the effects of fluency on alternative evaluative judgments (Winkielman et al., 2003). In fact, no other studies exist demonstrating the impact of conceptual fluency in the moral domain. In addition, while the theory on processing fluency assumes that fluency could render any stimulus more positive, most fluency studies show effects for neutral or new stimuli, mostly perceptual ones. This paper, on the other hand, uses behavior descriptions, which are complex, linguistic stimuli with very clear valence connotations. Our results show that fluency effects may be more general and robust than shown in previous research, as fluency may indeed not only render neutral stimuli positive or negative, but also render positive and negative stimuli more positive.
Our findings also support a reinterpretation of previous research findings, such as the notion that participants in a room with slightly dimmed lighting cheat more and earn more undeserved money than those in a well-lit room (Zhong, Bohns, \& Gino, 2010). The authors explain these findings by means of anonymity, but they also might be evidence of altered moral judgments due to fluency effects. Darkness is often related to badness (Meier et al., 2004), so a darker room could make it easier to think of behaviors related to cheating and dishonesty. Such fluency could prompt a sense of greater moral acceptability of these behaviors and thus increase the likelihood of displaying such behavior. Further research is needed to test this reinterpretation, but our findings imply that negative behavior might be tolerated more in the presence of negative cues (e.g., petty crime in red light districts).

Ultimately, these findings raise several questions for further research. First, it is important to investigate to what extent our findings generalize to other cues and situations. It remains unclear if other negatively valenced cues (e.g., symbols, pictures) lead to similar valence mismatch effects. More generally, being in a negative mood or being oriented toward preventing negative outcomes could render unwanted behavior more acceptable. In addition, we do not know if color cues also affect consumption experiences. For example, if a patient expects a cough syrup to taste bad, might this syrup taste better if the package uses red colors or depicts negative elements or symbols? At the same time, further research should take a closer look at possible boundary conditions. For instance, drawing on previous research (Tsai \& McGill, 2011), we might expect that the conceptual (dis)fluency effect is limited to people processing the information at lower (vs. higher) construal levels.

Second, in our studies participants merely saw descriptions of behaviors and had to judge their moral acceptability. One may wonder whether moral acceptability is also affected when these behaviors are part of a more complex message aimed at deterring undesirable or inciting desirable behavior. Although not mentioned for space constraints, we did find similar valence match effects on moral acceptability of behavior that was the focus of a prevention or promotion campaign. Still, future research might investigate the actual effects on behavior or intentions rather than on moral acceptability ratings.

Third, drawing on affective priming, we argue that negative messages are easier to process in the presence of negative cues. However, in affective priming paradigms, the primes and targets are very simple (e.g., single words and pictures) and automatically activate the associated valence. While our results suggest that affective priming effects may be obtained for more complex targets like sentences describing a behavior, it also raises the question of how valence of those complex targets is determined. A message designed to deter people from engaging in unwanted behavior by definition involves a negatively valenced behavior, but the message itself, by advocating an avoidance of something negative, seems positive. Still, prevention campaigns usually try to persuade people from avoiding something that they enjoy, such that they imply some restriction on individual freedom and thus could create a negative connotation. Additional research should investigate whether message valence is determined by 
message content or by message purpose. Further, while we find that "negative" behaviors on a negative background are regarded as less negative, participants in Study 2 seemingly do not interpret the negative behaviors as negative (mean acceptability score of 4.28 in the neutral condition). Possibly, these scores reflect personal acceptance rather than normative acceptance. Valence (mis)matches may be determined more by normative acceptability rather than personal acceptability. Future research is needed to test this possibility.

Fourth, we attribute the effects we obtain to conceptual (dis) fluency. While conceptual fluency may indeed operate, we offer no direct evidence to support this. Future research should aim to test this underlying process by manipulating cognitive load or by including measures of ease of processing or response time during judgment. In addition, it is important to examine whether the obtained effects are due to valence connotations or rather because the color cues function as go/no-go signals that may incite approach and avoidance behavior, respectively. A particularly nagging issue for further research involves the question whether fluency and disfluency operate similarly such that fluency makes judgments more positive and disfluency makes them more negative. Extant theorizing on fluency would indeed expect this to be the case. Our results of Study 2, however, indicate that fluency may indeed render judgments more positive, but we did not obtain more negative judgments in the presumably disfluent conditions in case of desirable behaviors. Future research is needed to investigate under what conditions fluency and disfluency may dissociate.

Finally, future studies should examine the viability of alternative explanations. Several alternative explanations may come to mind. First, one could argue that valence incongruency would result in less thorough processing, thereby resulting in less polarized judgments. This explanation, however, only holds for the results obtained for the desirable behavior. An explanation that proposes that the colors red and green may bring to mind a set of respectively negative and positive behaviors that serve as reference points for the judgmental behavioral stimuli and polarize evaluations in the mismatch conditions is equally inconsistent with the results obtained for desirable behaviors. A more challenging alternative explanation proposes that valence (in)congruency affects mood rather than processing fluency. In line with mood-as-information theory (Clore, Schwarz, \& Conway, 1994; Schwarz \& Clore, 1983), any mood effect may bias subsequent evaluative judgments, like the moral acceptability judgments in our studies. Although more research is needed to tease out the exact mechanism, for now, our studies show that the use of negative color cues in campaigns aimed to prevent unwanted behavior may be ill advised.

\section{References}

Adams, L., Faseur, T., \& Geuens, M. (2011). The influence of the self-regulatory focus on the effectiveness of stop-smoking campaigns for young smokers. Journal of Consumer Affairs, 45(2), 275-305.

Bagchi, R., \& Cheema, A. (2013). The effect of red background color on willingness-to-pay: The moderating role of selling mechanism. Journal of Consumer Research, 39, http://dx.doi.org/10.1086/666466.
Braun, C. C., \& Silver, N. C. (1995). Interaction of signal word and color on warning labels: Differences in perceived hazard and behavioral compliance. Ergonomics, 38(11), 2207-2220.

Cabeza, R., \& Ohta, N. (1993). Dissociating conceptual priming, perceptual priming, and explicit memory. European Journal of Cognitive Psychology, $5(1), 35-53$.

Cavazza, N., Graziani, A. R., Serpe, A., \& Rubichi, S. (2010). Right-wing face, left-wing face: The matching effect in the realm of political persuasion. Social Influence, 5(1), 1-22.

Chan, A. H. S., \& Ng, A. W. Y. (2009). Perceptions of implied hazard for visual and auditory alerting signals. Safety Science, 47(3), 346-352.

Clore, G. L., Schwarz, N., \& Conway, M. (1994). Affective causes and consequences of social information processing. In R. S. Wyer, \& T. Srull (Eds.), (2nd ed.). The handbook of social cognition, Vol. 1. (pp. 323-417) Mahwah, N.J.: Lawrence Erlbaum Associates.

De Houwer, J. (2011). Evaluative conditioning: A review of functional knowledge and mental process theories. In T. R. Schachtman, \& S. Reilly (Eds.), Applications of learning and conditioning (pp. 399-416). Oxford, UK: Oxford University Press.

Deng, X., Hui, S. K., \& Hutchinson, J. W. (2010). Consumer preferences for color combinations: An empirical analysis of similarity-based color relationships. Journal of Consumer Psychology, 20(4), 476-484.

Elliot, A. J., \& Maier, M. A. (2007). Color and psychological functioning. Current Directions in Psychological Science, 16(5), 250-254.

Elliot, A. J., Maier, M. A., Binser, M. J., Friedman, R., \& Pekrun, R. (2009). The effect of red on avoidance behavior in achievement contexts. Personality and Social Psychology Bulletin, 35(3), 365-375.

Elliot, A. J., Maier, M. A., Moller, A. C., Friedman, R., \& Meinhardt, J. (2007). Color and psychological functioning: The effect of red on performance attainment. Journal of Experimental Psychology. General, 136(1), 154-168.

Fazio, R. H. (2001). On the automatic activation of associated evaluations: An overview. Cognition and Emotion, 15(2), 115-141.

Friedman, R. S., \& Förster, J. (2002). The influence of approach and avoidance motor actions on creative cognition. Journal of Experimental Social Psychology, 38(1), 41-55.

Friedman, R. S., \& Förster, J. (2005). Effects of motivational cues on perceptual asymmetry: Implications for creativity and analytical problem solving. Journal of Personality and Social Psychology, 88(2), 263-275.

Haidt, J. (2001). The emotional dog and its rational tail: A social intuitionist approach to moral judgment. Psychological Review, 108(4), 814-834.

Hofmann, W., De Houwer, J., Perugini, M., Baeyens, F., \& Crombez, G. (2010). Evaluative conditioning in humans: A meta-analysis. Psychological Bulletin, 136(3), 390-421.

Jones, T. M. (1991). Ethical decision making by individuals in organizations: An issue-contingent model. Academy of Management Review, 16(2), 366-395.

Kahle, L. R., \& Homer, P. M. (1985). Physical attractiveness of the celebrity endorser: A social adaptation perspective. Journal of Consumer Research, 11(4), 954-961.

Kamins, M. A. (1990). An investigation into the 'match-up' hypothesis in celebrity advertising: When beauty may be only skin deep. Journal of Advertising, 19(1), 4-13.

Klauer, K. C., \& Musch, J. (2003). Affective priming: Findings and theories. In J. Musch, \& K. C. Klauer (Eds.), The psychology of evaluation: Affective processes in cognition and emotion (pp. 7-49). Mahwah, NJ: Erlbaum.

Kohlberg, L. (1976). Moral stages and moralization: The cognitive developmental approach. In T. Lickona (Ed.), Moral development and behavior (pp. 31-53). New York: Holt, Rinehart \& Winston.

Kwallek, N., \& Lewis, M. (1990). Effects of environmental color on males and females: A red or white or green office. Applied Ergonomics, 21(4), 275-278.

Lee, A. Y. (2002). Effects of implicit memory on memory-based versus stimulus-based brand choice. Journal of Marketing Research, 39(4), $440-454$.

Lee, A. Y., \& Labroo, A. A. (2004). The effect of conceptual and perceptual fluency on brand evaluation. Journal of Marketing Research, 41(2), 151-165.

Lindsey, D. T., Brown, A. M., Reijnen, E., Rich, A. N., Kuzmova, Y. I., \& Wolfe, J. M. (2010). Color channels, not color appearance or color categories, guide visual search for desaturated color targets. Psychological Science, 21(9), 1208-1214. 
Mayer, N. D., \& Tormala, Z. L. (2010). "Think" versus "feel” framing effects in persuasion. Personality and Social Psychology Bulletin, 36(4), 443-454.

Mehta, R., \& Zhu, R. J. (2009). Blue or red? Exploring the effect of color on cognitive task performances. Science, 323(5918), 1226-1229.

Meier, B. P., Robinson, M. D., \& Clore, G. L. (2004). Why good guys wear white: Automatic inferences about stimulus valence based on brightness. Psychological Science, 15(2), 82-87.

Pandelaere, M., Millet, K., \& Van den Bergh, B. (2010). Madonna or Don McLean? The effect of order of exposure on relative liking. Journal of Consumer Psychology, 20(4), 442-451.

Piaget, J. (1965). The moral judgment of the child. New York: The Free Press.

Reber, R., Schwarz, N., \& Winkielman, P. (2004). Processing fluency and aesthetic pleasure: Is beauty in the perceiver's processing experience? Personality and Social Psychology Review, 8(4), 364-382.

Reber, R., Winkielman, P., \& Schwarz, N. (1998). Effects of perceptual fluency on affective judgments. Psychological Science, 9(1), 45-48. Rest, J. R. (1986). Moral development: Advances in research and theory. New York: Praeger.

Schwarz, N., \& Clore, G. L. (1983). Mood, misattribution, and judgments of well-being: Informative and directive functions of affective states. Journal of Personality and Social Psychology, 45(3), 513-523.

Shah, A. K., \& Oppenheimer, D. M. (2007). Easy does it: The role of fluency in cue weighting. Judgment and Decision Making, 2(6), 371-379.

Simonson, I. (2008). Will I like a "medium" pillow? Another look at constructed and inherent preferences. Journal of Consumer Psychology, 18(3), 155-169.

Spruyt, A., Hermans, D., De Houwer, J., Vandromme, H., \& Eelen, P. (2007). On the nature of the affective priming effect: Effects of stimulus onset asynchrony and congruence proportion in naming and evaluative categorization. Memory \& Cognition, 35(1), 95-106.

Stone, N. J. (2003). Environmental view and color for a simulated telemarketing task. Journal of Environmental Psychology, 23(1), 63-78.

Tsai, C. I., \& McGill, A. L. (2011). No pain, no gain? How fluency and construal level affect consumer confidence. Journal of Consumer Research, 37(5), 807-821.

Tulving, E., \& Schacter, D. L. (1990). Priming and human memory systems. Science, 247(4940), 301-306.

Turiel, E. (1983). The development of social knowledge: Morality and convention. Cambridge, England: Cambridge University Press.

Whittlesea, B. W. A. (1993). Illusions of familiarity. Journal of Experimental Social Psychology: Learning, Memory, and Cognition, 19(6), 1235-1253.

Winkielman, P., Schwarz, N., \& Belli, R. F. (1998). The role of ease of retrieval and attribution in memory judgments-Judging your memory as worse despite recalling more events. Psychological Science, 9(2), 124-126.

Winkielman, P., Schwarz, N., Fazendeiro, T., \& Reber, R. (2003). The hedonic marking of processing fluency: Implications for evaluative judgment. In J. Musch, \& K. C. Klauer (Eds.), The psychology of evaluation: Affective processes in cognition and emotion (pp. 189-217). Mahwah, NJ: Erlbaum Associations, Inc.

Zhao, G. Z., \& Pechmann, C. (2007). The impact of regulatory focus on adolescents' response to antismoking advertising campaigns. Journal of Marketing Research, 44(4), 671-687.

Zhong, C. B., Bohns, V. K., \& Gino, F. (2010). Good lamps are the best police: Darkness increases dishonesty and self-interested behavior. Psychological Science, 21(3), 311-314. 